\title{
Improving E. coli growth performance by manipulating small RNA expression
} CrossMark

\author{
Alejandro Negrete ${ }^{1,2+}$ and Joseph Shiloach ${ }^{1 *}+$ (D)
}

\begin{abstract}
Efficient growth of E. coli, especially for production of recombinant proteins, has been a challenge for the biotechnological industry since the early 1970s. By employing multiple approaches, such as different media composition, various growth strategies and specific genetic manipulations, it is now possible to grow bacteria to concentrations exceeding $100 \mathrm{~g} / \mathrm{L}$ and to achieve high concentrations of recombinant proteins. Although the growth conditions are carefully monitored and maintained, it is likely that during the growth process cells are exposed to periodic stress conditions, created by fluctuations in $\mathrm{pH}$, dissolved oxygen, temperature, glucose, and salt concentration. These stress circumstances which can occur especially in large volume bioreactors, may affect the growth and production process. In the last several years, it has been recognized that small non-coding RNAs can act as regulators of bacterial gene expression. These molecules are found to be specifically involved in E. coli response to different environmental stress conditions; but so far, have not been used for improving production strains. The review provides summary of small RNAs identified on petri dish or in shake flask culture that can potentially affect growth characteristics of E. coli grown in bioreactor. Among them MicC and MicF that are involved in response to temperature changes, RyhB that responds to iron concentration, Gady which is associated with lower $\mathrm{pH}$, Sgrs that is coupled with glucose transport and OxyS that responds to oxygen concentration. The manipulation of some of these small RNAs for improving growth of $E$. coli in Bioreactor is described in the last part of the review. Overexpression of SgrS was associated with improved growth and reduced acetate expression, over expression of GadY improved cell growth at acidic conditions and over expression of OxyS reduced the effect of oxidative stress. One of the possible advantages of manipulating sRNAs for improving cell growth is that the modifications occur at a post-translational level. Therefore, the use of sRNAs may exert minimal effect on the overall bacterial metabolism. The elucidation of the physiological role of newly discovered sRNAs will open new possibilities for creating strains with improved growth and production capabilities.
\end{abstract}

Keywords: Small RNA, Stress response, High cell density cultures, E. coli, Acetate production

\section{Background}

Escherichia coli is the preferred platform for industrial production of various biological products due to its short doubling time, ability to grow to high cell densities, the relatively simple scale-up procedure, cost-effectiveness, known genomics, as well capability to express high concentrations of recombinant proteins [1-4]. Of the 94

\footnotetext{
*Correspondence: Josephs@niddk.nih.gov

${ }^{\dagger}$ Alejandro Negrete and Joseph Shiloach contributed equally to this manuscript

1 Biotechnology Core Laboratory, NIDDK, NIH, Bethesda, MD 20892, USA

Full list of author information is available at the end of the article
}

protein-based anti-cancer pharmaceuticals currently on the market, $70 \%$ are produced in $E$. coli $[5,6]$.

Production of biologicals from $E$. coli is typically done by growing the microorganism to high density, a procedure that was developed in the mid 1970s [7], and is currently the method of choice $[6,8]$. Achieving high cell concentration of the bacteria is done by adequate supply of nutrients, such as carbon sources (mostly glucose) and dissolved oxygen and by controlling growth parameters such as $\mathrm{pH}$ and temperature. Although the growth parameters are being controlled, fluctuations in osmolality, temperature, dissolved oxygen, substrates, and metabolites concentration such as glucose, acetate and ammonia can affect bacterial growth and production capability [9]. 
Bacterial strains resistant to stress are expected to exhibit improved growth and recombinant protein production. Genetic engineering approaches have generated strains resistant to stress $[8,10-13]$. However, the genetic modifications were usually associated with lower cell concentrations or production of metabolites that affect the overall process efficiency $[8,11]$. E. coli responds to different stress parameters by initiating responses through the activation of complex physiological and molecular mechanisms $[14,15]$. In the past few years, it has been recognized that small RNAs play a role as regulators of bacterial gene expression $[16,17]$. These molecules were found to be involved in $E$. coli response to different environmental stresses [18-20]. About 100 sRNAs were discovered by microarrays, biocomputational prediction algorithms and confirmed by reporter gene tags, northern blots, or pulse-expression [21-23]. The functions of only a few have been identified by experimental methods such as specific binding of the sRNA to its target, verifying the stress conditions that triggered its expression, and showing the evidence of its physiological effect [24]. In this review, we are focusing on those small RNAs that can potentially enhance bacterial response to stress especially when grown to high cell densities in bioreactors.

\section{Small RNAs respond to stress during $E$. coli growth in shake flasks}

Most of the information on sRNAs involvement in response to stressed growth conditions was obtained from $E$. coli growing to low density in shake flask. The data obtained from these studies identified several sRNAs responding to stress including temperature, osmolarity, iron limitation, glucose phosphate accumulation, $\mathrm{pH}$, and oxygen. All these studies concentrated only on understanding the molecular response of the sRNA to the stress, but not on the possible physiological implications of manipulating the expression of these sRNA. The information currently known is summarized in Table 1.

\section{Temperature}

Two sRNAs, MicC and MicF, were identified to be involved in the regulation of translation and stability of porins [49]. Both were found to be associated with response to temperature changes. MicC was expressed at low temperature $\left(24{ }^{\circ} \mathrm{C}\right)$ and was identified by growing E. coli K-12 (JM109) in LB and in M9-glycerol minimal media at different temperatures at a stationary and at an exponential phases to an $\mathrm{OD}_{600}$ of 0.2 or 0.4 [25]. MicF was found to be expressed at higher temperatures (37 or $42{ }^{\circ} \mathrm{C}$ ) and was identified by growing E. coli $\mathrm{K}-12$ JA221 overnight to an $\mathrm{OD}_{550}$ of 0.2 which was followed by increasing the growth temperature to $37^{\circ} \mathrm{C}$ by adding equal volume of medium at $50{ }^{\circ} \mathrm{C}$ [32]. Another sRNA responding to temperature change is DsrA, this sRNA was found to be induced in E. coli $\mathrm{K}-12$ cultures grown in $\mathrm{LB}$ media at $24{ }^{\circ} \mathrm{C}$ to an $\mathrm{OD}_{600}$ of $0.4-0.6$ [27]. DsrA is a sRNA that regulates rpoS and hns mRNAs [29]. This sRNA interacts with the mRNA of the transcriptional regulator $\sigma^{\mathrm{S}}$ (encoded by rpoS) and the transcriptional repressor H-NS [50], it activates RpoS translation and inhibits hns translation [29, 30].

\section{Osmolarity}

The sRNA MicF, in addition to its response to temperature change, has also been associated with high osmolarity conditions created by adding $20 \%$ sucrose to the growth media. MicF expression was increased when $E$. coli $\mathrm{K}-12$ was grown in LB, low-phosphate medium, or in nutrient broth or in M9 medium supplemented with $0.4 \%$ glucose, MicF expression was increased when the culture was exposed to high osmolarity conditions [26].

Another sRNA responding to changes in osmolarity is RprA, a sRNA of 105nt that activates RpoS translation when the bacteria are exposed to osmotic shock [33, 34]. Experiments were performed by growing E. coli $\mathrm{K}-12$ (MG1655) in LB to stationary phase $\left(\mathrm{OD}_{600}=3.5\right)$ and the addition of $0.12,0.23,0.46$ or $1.0 \mathrm{M}$ sucrose for $20 \mathrm{~min}$ [34]. RprA expression has also been induced by osmotic shock in an E. coli K-12 MC1061 strain grown in LB to an $\mathrm{OD}_{600}$ of 0.3 by adding $0.46 \mathrm{M}$ sucrose [33].

\section{Iron concentration}

The transcription of RyhB, a 90 nt sRNA, was found to be associated with iron availability in the media. RyhB is usually repressed at iron-rich conditions [51] and is expressed when the iron concentration is low, thereby reducing iron consumption by downregulating the expression of iron-containing proteins and, as a result, increasing the concentration of free intracellular $\mathrm{Fe}^{3+}[51$, 52]. This was studied by using derivatives of $E$. coli $\mathrm{K}-12$ MG1655 that were grown in M63 media supplemented with $1 \mu \mathrm{M} \mathrm{FeSO}_{4}$ [52]. Other studies to access the effect of high iron concentration were conducted by growing $E$. coli K-12 MG1655 to an $\mathrm{OD}_{600}=0.3$ in LB or M63 media supplemented with $0.2 \%$ glycerol at $50 \mu \mathrm{M} \mathrm{FeSO}{ }_{4}$ [35]. These showed that increased RyhB expression triggered reduced expression of genes associated with the TCA cycle and the respiratory chain such as $a c n A$ (aconitase), $s d h C D A B$ (succinate dehydrogenase), $\operatorname{sod} B$ (superoxide dismutase), fumA (fumarase), and ferritins $b f r$ and $f t n A$ $[35,36]$.

pH

The sRNA GadY has been linked with increased expression of genes associated with response to acidic 
Table $1 \mathrm{Hfq}$-dependent sRNAs involved in the stress response of $E$. coli growing in bioreactor

\begin{tabular}{|c|c|c|c|c|c|}
\hline Stressor & RNA & Length & Regulation & Physiological response & References \\
\hline \multirow[t]{3}{*}{ Temperature } & $\mathrm{MicC}$ & 109 & Increased at low temperature & Repression of porin synthesis OmpC & {$[25]$} \\
\hline & $\mathrm{MicF}$ & 93 & Increased at high temperature & $\begin{array}{l}\text { Repression of translation and stability of porin } \\
\text { OmpF }\end{array}$ & {$[26]$} \\
\hline & Dsra & 87 & Increased at low temperature & $\begin{array}{l}\text { Activation of translation of rpos and inhibition of } \\
\text { translation of hns }\end{array}$ & {$[27-30]$} \\
\hline \multirow[t]{2}{*}{ Osmolarity } & $\mathrm{MicF}$ & 93 & Induced by high osmolarity & $\begin{array}{l}\text { Repression of translation and stability of porin } \\
\text { OmpF }\end{array}$ & {$[31,32]$} \\
\hline & RprA & 105 & Induced by high osmolarity & Activation of translation of rpos & {$[32-34]$} \\
\hline Iron & RyhB & 90 & Induced by limited iron & $\begin{array}{l}\text { Repression of iron enzymes, TCA cycle and } \\
\text { respiratory chain }\end{array}$ & {$[35,36]$} \\
\hline \multirow[t]{2}{*}{ Oxygen } & OxyS & 109 & $\begin{array}{l}\text { Induced by oxidative stress }\left(\mathrm{H}_{2} \mathrm{O}_{2}\right) \text {; activated by } \\
\text { OxyR }\end{array}$ & $\begin{array}{l}\text { Repression of unneeded activities and protec- } \\
\text { tion against mutagenesis }\end{array}$ & {$[37]$} \\
\hline & FnrS & 113 & $\begin{array}{l}\text { Induced under anaerobic conditions; activated } \\
\text { by FNR, ArcA and CRP }\end{array}$ & $\begin{array}{l}\text { Repression of genes from anaerobic metabolism } \\
\text { and oxidative stress }\end{array}$ & {$[38,39]$} \\
\hline \multirow[t]{3}{*}{ Glucose } & SgrS & 227 & $\begin{array}{l}\text { Induced by glucose-phosphate or analogs; } \\
\text { activated by SgrR }\end{array}$ & $\begin{array}{l}\text { Prevent sugar uptake, reduce accumulated } \\
\text { sugar-phosphates by repressing pts } G \text { synthesis }\end{array}$ & {$[40,41]$} \\
\hline & CyaR & 87 & Induced by low glucose; activated by CRP & $\begin{array}{l}\text { Repression of porin synthesis, membrane pro- } \\
\text { teins, and synthetase enzymes }\end{array}$ & {$[42]$} \\
\hline & Spot42 & 109 & Induced by glucose; repressed by CRP & $\begin{array}{l}\text { Decrease galactose utilization and non-preferred } \\
\text { carbon source metabolism }\end{array}$ & {$[43,44]$} \\
\hline \multirow[t]{3}{*}{$\mathrm{pH}$} & GadY & $105,90,59$ & Induced by low pH & Activation of acid resistance genes from the GDS & {$[45,46]$} \\
\hline & RprA & 105 & Induced by low pH & Activation of translation of rpos & {$[47]$} \\
\hline & Dsra & 87 & Increased at low pH & Activation of translation of rpos & {$[47,48]$} \\
\hline
\end{tabular}

conditions. There are three species of the GadY sRNA: full-length GadY at $105 \mathrm{nt}$ and two processed forms at 90 and 59 nt respectively; all detected when E. coli K-12 MC4100 and E. coli K-12 MG1655 were grown in shake flasks in LB at pH 5.8 [45]. In a different experiment, GadY and its processed forms were detected in in E. coli grown to $\mathrm{OD}_{600}$ of 2.0 in LB-MES media buffered at $\mathrm{pH}$ 5.5 with $100 \mathrm{mM}$ 2-(N-morpholino)ethanesulfonic acid (MES) [46].

Overexpression of GadY was associated with activation of the acid resistance genes $\operatorname{gad} A, \operatorname{gadB}$, and $\operatorname{gad} C$ (part of the GDS-glutamate decarboxylase system), which in turn activated the GadX mRNA, inducing the expression of GDS [45, 53, 54]. GadY was also found to activate the Lysine decarboxylase system (LDS) at $\mathrm{pH}$ 5.8 [55]. Two other sRNAs RprA and DsrA have been associated with acid resistance [47]. The RprA and DsrA were expressed when E. coli K-12 MG1655 cells were grown in M9 media supplemented with $0.4 \%$ glucose. The culture was diluted $1: 10$ or 1:100 with M9 minimal media supplemented with $0.4 \%$ glucose and $1.5 \mathrm{mmol} / \mathrm{L}$ glutamate, which was adjusted to $\mathrm{pH} 2.0$ or 3.0 with concentrated $\mathrm{HCl}$ [47]. RprA induces the expression of rpoS which protects against acid resistance [47]. The overexpression of DsrA induces rpoS similarly to the RprA sRNA [48].

\section{Glucose transport and glucose phosphate accumulation}

Expression of the glucose transporter ptsG was found to be regulated at the posttranscriptional level by the $227 \mathrm{nt}$ sRNA SgrS that binds to the mRNA ptsG $[40,56]$. The effect of SgrS was observed when E. coli K-12 (MG1655) grew in M63 minimal media agar plates supplemented with $0.2 \%$ glucose, and in liquid LB medium supplemented with $1 \%$ of glucose or the non-metabolized glucose alpha methyl glucoside $(\alpha M G)[40,57]$. It was established that SgrS is expressed in response to glucose-6-phosphate accumulation, inhibiting the translation of the ptsG mRNA, and as result causing decrease of the glucose transporter $\mathrm{IICB}^{\mathrm{Glc}}$ and glucose entry into the cells [58-61]. SgrS also encodes the 43 amino acids polypeptide SgrT that regulates the activity of preexisting $\mathrm{IICB}^{\mathrm{Glc}}$ transporters [41]. This polypeptide rescues cells growing in the presence of $\alpha M G$ by reducing glucose transport independently of mRNA degradation [41, 62]. Other sRNAs that are associated with carbon metabolism are CyaR and Spot42. CyaR an 87 nt sRNA, is induced at low glucose concentrations and is positively regulated by the global regulator Crp [42]. This was studied by growing E. coli in shake flask or agar plates containing Lennox broth or M63 minimal medium supplemented with $0.001 \%$ vitamin B1 and 0.2\% glucose or glycerol [42]. Overexpression of CyaR downregulated at least 25 additional genes, responsible for the expression of membrane proteins, transporters, 
and essential enzymes to adapt cells to low glucose conditions [42]. Spot42 is a109 nt Hfq-dependent sRNA that represses genes involved in central and secondary metabolism, redox balancing, and consumption of various nonpreferred carbon sources resulting in slow growth [63]. The information above was obtained by growing $E$. coli $\mathrm{K}-12$ in LB or M9 media supplemented with $10 \mu \mathrm{g} / \mathrm{mL}$ thiamine, $2 \mathrm{mM} \mathrm{MgSO}_{4}, 0.1 \mathrm{mM} \mathrm{CaCl}_{2}$, and $0.2 \%$ casamino acids, and different carbon sources [63].

\section{Oxygen}

The sRNA OxyS, is induced in response to increased expression of the OxyR regulon which was triggered by exposing E. coli $\mathrm{K}-12$, grown in $\mathrm{LB}$ media to $\mathrm{OD}_{600}=0.2$, to $\mathrm{H}_{2} \mathrm{O}_{2}$ [37]. OxyS acts post-transcriptionally by inhibiting rpoS and regulating the expression of FhlA (format hydrogen lyase activator) which protects the cells against mutagenesis [37, 64, 65].

High oxygen concentrations cause cellular damage by affecting enzymes, proteins, and DNA through the formation of reactive oxygen species (ROS). E. coli is protected against oxidative stress by activating the SoxRS and the OxyR regulons $[66,67]$. When $E$. coli $\mathrm{K}-12$, grown in LB or defined media, is exposed to superoxide or redoxcycling drugs, the SoxR regulon activates the soxS gene that acts as transcription factor, inducing the expression of several genes from the SoxRS regulon. Some of the genes activated by the SoxS protein are $\operatorname{sod} A, \operatorname{acn} A$, fumC, $m i c F$, and $z w f$, replacing sensitive enzymes such as aconitase $B$ and fumarases $A$ and $B$ with the oxygen resistant isozymes aconitase $A$ and fumarase $C[68,69]$.

\section{Manipulation of sRNAs expression to improve high cell density $E$. coli growth in bioreactors}

The identification of the different small RNAs associated with stress growth conditions, described in the previous section, was performed when the bacterial culture was grown on petri dishes or in shake flasks at low density. The research focused on discovering which sRNA responded to a specific stress condition and on locating potential target genes and their possible physiological roles. This was elucidated by using molecular biology and computational predictive tools. Since shake flasks are mostly being used for low density growth at noncontrolled conditions, this approach did not provide sufficient information on the possible role of sRNAs on $E$. coli growth in bioreactor for biological production. At these growth conditions, especially when it is done to achieve high density growth, the bacteria are exposed to multiple stresses as a result of high nutrient and metabolite concentrations, changes in $\mathrm{pH}$, dissolved oxygen, and temperature that can affect their growth and production capability [13]. Since some sRNAs were found to respond to bacterial stress, their overexpression or inhibition can potentially affect the bacterial growth and production properties especially at high cell density culture in a bioreactor. E. coli strains with modified sRNA expression will potentially be more resistant to stress and thus more suitable for industrial production. The following section summarizes the information currently available on utilizing sRNAs for creating $E$. coli strains less susceptible to environmental stresses, specifically $\mathrm{pH}$, oxygen concentration, glucose, and acetate.

\section{Effect of SgrS manipulation on acetate in high cell density growth of $E$. coli}

Growing E. coli to high cell densities is done, in most cases, by supplying the growing culture with adequate supply of glucose. However, glucose is also associated with acetate production that negatively affects the bacterial growth and, as a result, various growth strategies are routinely implemented, together with genetic construction of bacterial strains, to minimize acetate production and allow the bacteria to grow and produce without interruption [70,71]. These growth strategies were focused on controlling the glucose supply rate, and on altering the central carbon metabolism by diverting the metabolic flux through increasing glucose uptake, manipulating the gene cra or modifying the phosphotransferase system (PTS). Although, these approaches solved the acetate accumulation they were associated with lower cell densities [72-76].

Several studies reported reduction in acetate excretion by knocking down the $p t s G$ gene, which is responsible for coding the glucose-specific enzyme II of the PTS. This approach minimized the acetate excretion by reducing the glucose uptake which decreased the flux through glycolysis. However, the growth rate of this mutant strain was slower than the parental strain [72]. The genetic manipulation of specific genes by overexpression or deletion frequently limits cell growth since the regulation of other genes is being affected [3]. Using sRNAs for reducing acetate excretion is an attractive approach, since the regulation occurs at the posttranscriptional level and, therefore, might not affect cell growth.

When transcription of the sRNA SgrS was evaluated in E. coli culture growing in shake flask, its expression increased when the bacteria were exposed to the nonmetabolizable glucose analog alpha methyl glucoside $(\alpha M G)$ which was associated with decreased expression of the glucose transporter ptsG, as seen in Fig. 1a [40, 77]. The increase in SgrS transcription and reduction in pts $G$ expression was observed in both $E$. coli B (BL21) and E. coli $\mathrm{K}-12$ (JM109 and MG1655). However, when both strains were exposed to high glucose concentration, SgrS transcription was dissimilar; it increased in E. coli $B$ and was not observed in E. coli K-12 (Fig. 1b). 
The increased SgrS transcription likely reduced the ptsG biosynthesis and lowered the bacterial glucose transport rate. This is an indication that E. coli $\mathrm{B}$ tolerates high glucose concentration, not only because of its more efficient central carbon metabolism [78] but also as a result of its ability to control the rate of glucose transport into the cells, thus minimizing the overflow of glucose and acetate production. The overexpression of SgrS in E. coli $\mathrm{B}$ was attributed to a possible accumulation of glucosephosphate suggesting a possible overflow of glucose. This did not happen in E. coli $\mathrm{K}-12$ perhaps because glucose was converted to acetate and pyruvate. Additionally, in high cell density cultures, the $\operatorname{SgrS}-p t s G$ interaction is activated by high glucose concentration and is specific to E. coli B.

Based on the above observations, an overexpression of the sRNA SgrS in E. coli K-12 seems to be a logical approach to increase the bacteria tolerance to high glucose concentration and to reduce acetate excretion. The behavior of E. coli $\mathrm{K}-12$ overexpressing SgrS grown in bioreactor at high glucose concentration is seen in Fig. 2 . Growth and glucose consumption in E. coli with plasmid control and with plasmid overexpressing SgrS described in Fig. 2a and acetate excretion of the two strains in Fig. 2b. It is obvious that SgrS expression minimized the negative effect of acetate accumulation on the cell growth, the low production of acetate without affecting cell growth suggest that the overexpressing SgrS strain is promising candidate for large scale production of recombinant proteins [79].

\section{Effect of GadY on growth of $E$. coli under acidic conditions}

Exposure to low $\mathrm{pH}$ is a common stress condition during $E$. coli growth in media supplemented with glucose can affect the bacterial growth rate and protein production efficiency. The main cause for a drop-in $\mathrm{pH}$ is the accumulation of acetic acid [80], and it is usually occurring at high density growth. Even when the culture $\mathrm{pH}$ is being kept around 7.0 (by adding base, such as ammonium hydroxide or sodium hydroxide), there is always the possibility of local regions in the bioreactor where the $\mathrm{pH}$ is low, as was identified when dissolved oxygen concentration was followed in different sections of the bioreactor [81, 82]. Bacterial strains resistant to low $\mathrm{pH}$ will, therefore, have an advantage compared with the parental strain. Creating such strains by manipulating small RNA expression seems to be an attractive option, since, unlike genetic manipulation of glucose utilization pathways [75], it is possible that the effect on the bacterial growth and metabolism will be minimal.

As described in the previous section, the small RNA GadY was expressed at low $\mathrm{pH}$ in cultures grown in shake flasks [45] but no explanation for the GadY

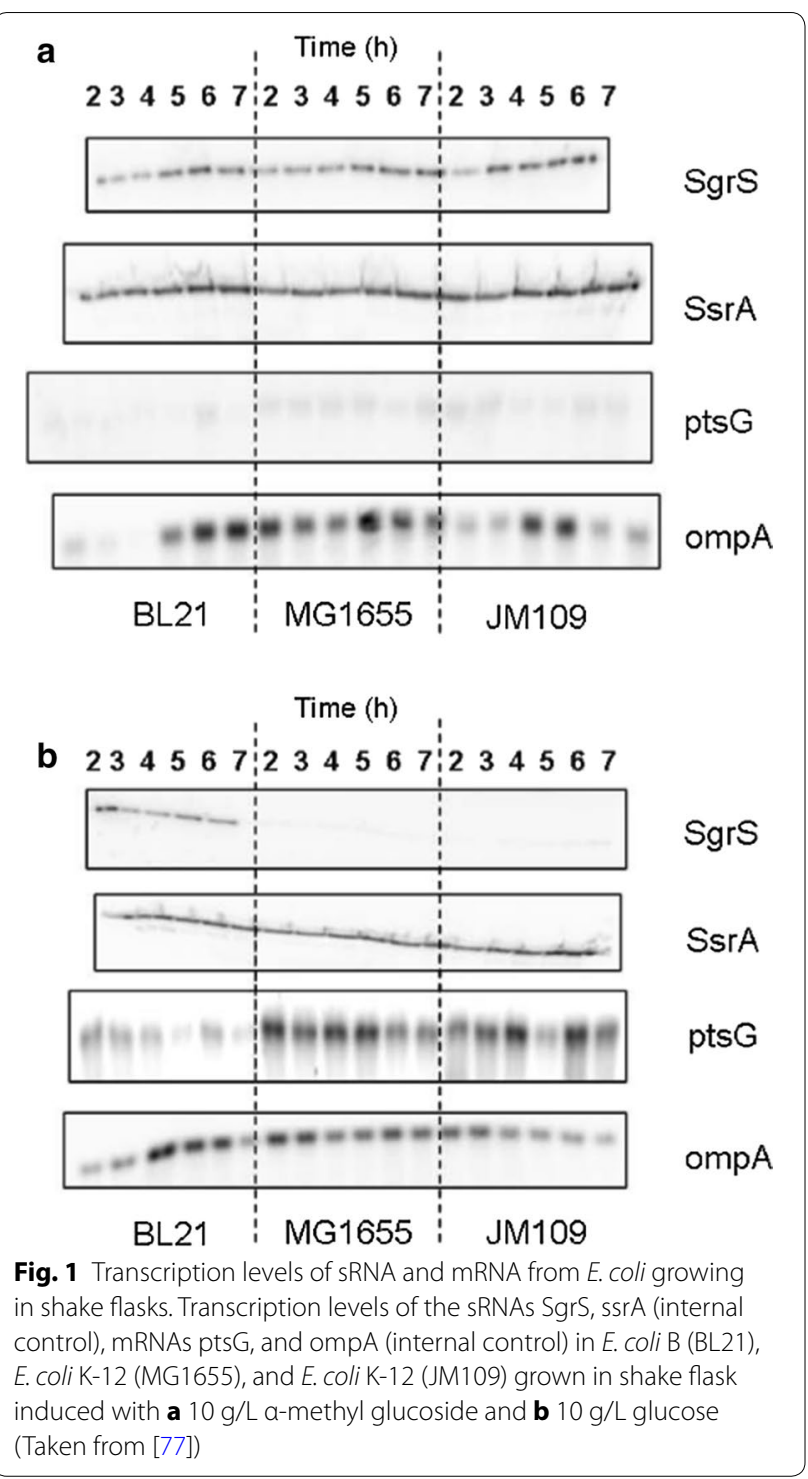

expression effect on the bacterial metabolism or growth was suggested. Expressing GadY was considered as a possible approach for creating a bacterial strain which may be less sensitive to low $\mathrm{pH}$. To test this concept, an E. coli K-12 strain (MG1655) expressing the sRNA GadY was created and its performance in high cell density cultures in a bioreactor was compared with its parental strain [81]. It was found that at $\mathrm{pH} 7.0$, both strains grew to a similar cell density of $\mathrm{OD}_{600}=43$, but the overexpressing GadY strain produced $40 \%$ less acetate than the parental strain. At pH 6.0, the parental strain (Fig. 3a) grew $35 \%$ less and produced $6 \mathrm{~g} / \mathrm{L}$ (200\%) more acetate than the GadY overexpressing strain (Fig. 3b) [81].

The overexpressing GadY strain was evaluated further by following its response to media acidification with 

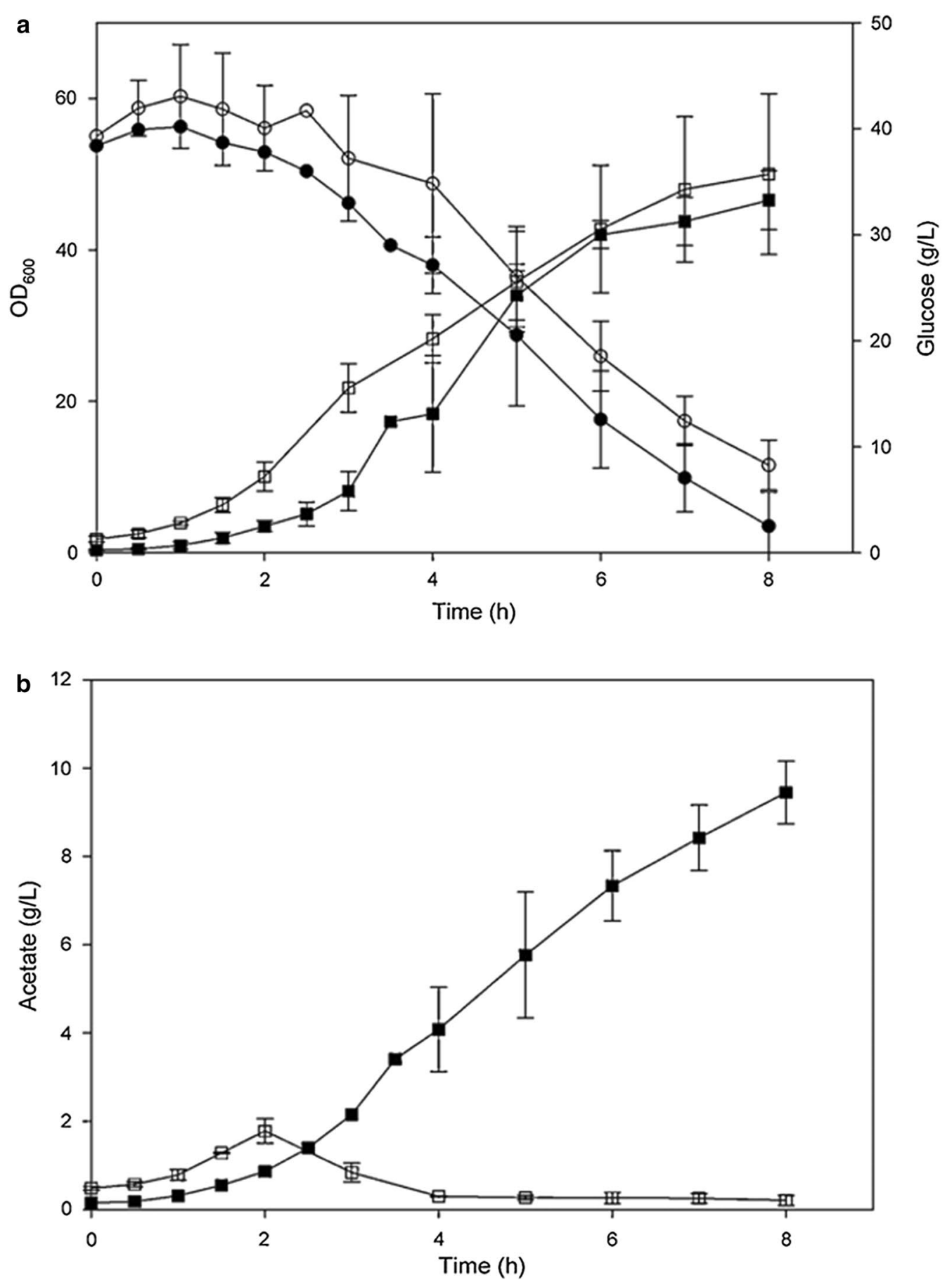

Fig. 2 Growth, glucose consumption and acetate production in E. coli K-12(MG1655) and E. coli K-12 (MG1655 laclq) containing plasmid pLCV1 overexpressing SgrS. a Growth and glucose consumption in (filled square, filled circle) E. coli K-12 (MG1655) and in (open square, open circle) E. coli K-2 (MG1655 laclq) over-expressing SgrS. b Acetate excretion in (filled square) E. coli K-12 (MG1655) and in (open square) E. coli K-2 (MG1655 laclq) over-expressing SgrS (Taken from [79])

various organic acids [81]. The strain was exposed to $\mathrm{pH}$ 6.0 by adding acetic or phosphoric acid to the growth media (Fig. 4). The results showed that the overexpression GadY strain responded better than the parental strain to the acid addition and, that at the same $\mathrm{pH}$, the acetic acid (Fig. 4a) affected the bacterial growth more than the phosphoric acid (Fig. 4b). Further analysis was performed by determining the expression level of 17 

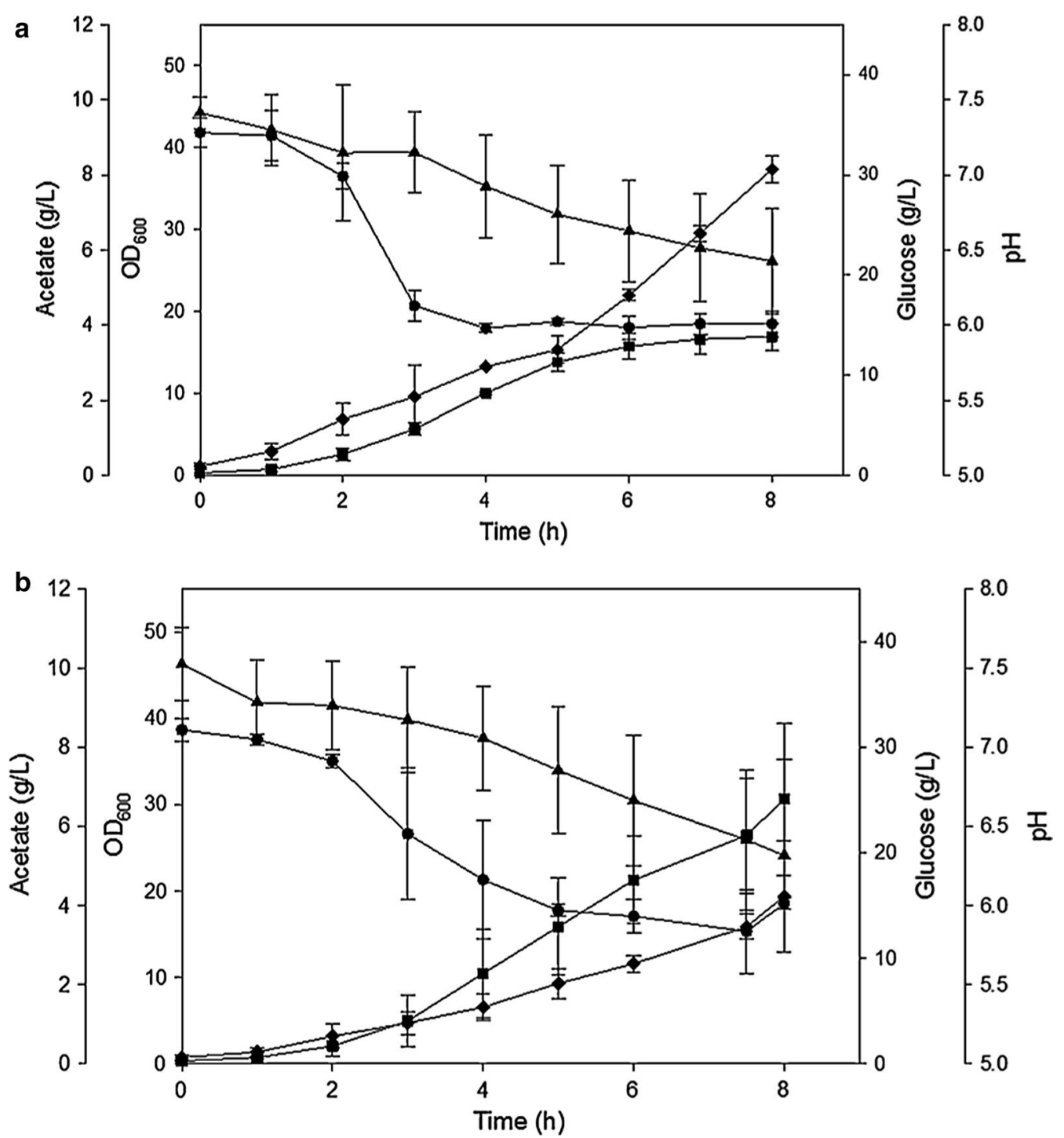

Fig. 3 Cell growth parameters of E. coli MG1655 growing in bioreactor at pH 6.0 naturally decreased. a Parental strain and b GadY strain. (Square) $\mathrm{OD}_{600}$ (triangle) glucose (g/L) (diamond) acetate (g/L), and (circle) pH (Taken from [81])

sRNAs that were previously reported to be associated with acid stress [83]. The results showed that in both strains growing at $\mathrm{pH} 7.0$ the lysine decarboxylase system (LDS) was expressed in the early exponential phase and the glutamate decarboxylase system (GDS) was expressed in the late exponential phase. At $\mathrm{pH} 6.0$, this pattern was similar except that the GDS was only expressed in the late exponential phase at the parental strain but not in the overexpressing GadY strain, an indication that GadY improved the growth of E. coli by deactivating the GDS system in the late exponential phase [81].

The overexpressing GadY strain was also found to decrease the production of acetate, regardless of the culture $\mathrm{pH}$, which reduced further its negative effect on cell growth. Acetate dissociation depends on the media $\mathrm{pH}$ and affects the internal $\mathrm{pH}$ of the cells $[80,84]$. Several processes and genetic approaches have been implemented to reduce acetate production, but some of these approaches had negative effects on cell growth and/or recombinant protein production [75]. An E. coli strain resistant to the acetate accumulation has an obvious advantage for high density growth and recombinant proteins production.

\section{Effect of OxyS on high cell density growth of $E$. coli}

The small RNA OxyS is over-expressed when E. coli is exposed to oxidative stress generated by $\mathrm{H}_{2} \mathrm{O}_{2}$ or redoxcycling drugs, which the bacterial culture is not exposed 

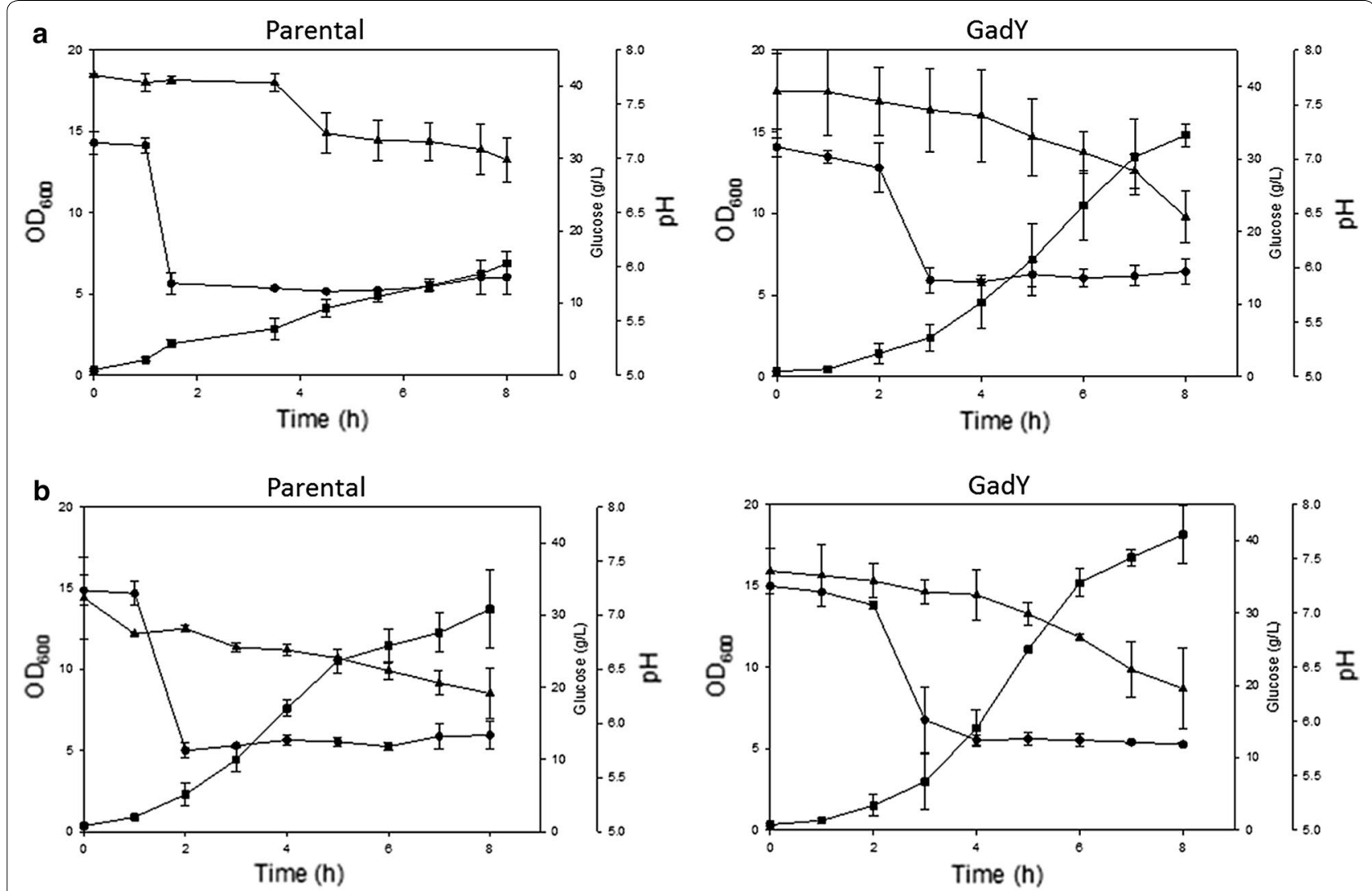

Fig. 4 Cell growth parameters of E. coli K-12 MG1655 parental and GadY strains growing in bioreactor at pH 6.0. At OD 2.0 the pH was decreased from pH 7.0 to $\mathrm{pH} 6.0$ by the addition of a acetic acid or $\mathbf{b}$ phosphoric acid. (Square) $\mathrm{OD}_{600}$ (triangle) glucose (g/L), and (circle) pH (Taken from [81])

to when it grown in shake flasks or in bioreactors [37, $69,85-87]$. To identify the possible role of this sRNA in high cell density cultures grown in bioreactor, its expression was followed when the bacterial culture was grown in the presence of high dissolved oxygen concentration. Supplying oxygen-enriched air or pure oxygen is a procedure commonly used to satisfy the oxygen demand of the bacterial culture $[88,89]$. It was found that high concentrations of molecular $\mathrm{O}_{2}$ in a bioreactor caused the activation of the superoxide stress regulator SoxRS, which induces the transcription of the $\operatorname{soxS}$ and the $\operatorname{sod} A$ genes [90]. The $\operatorname{sod} A$ gene encodes the manganese superoxide dismutase (SOD), which allows the cells to continue growing during the oxidative stress [91]. The SoxRS and SOD system have been described as the major protection mechanisms against the toxic effects of pure $\mathrm{O}_{2}$. The main response of the cells to the oxygen stress was through the soxRS regulon (Fig. 5a) although there was a small increase in the OxyS expression, from the oxyR regulon (Fig. 5b) [90].

The OxyR, which activates the expression of the sRNA OxyS, is a transcriptional dual regulator responding to oxidative stress, mainly to high concentrations of $\mathrm{H}_{2} \mathrm{O}_{2}$. This regulon includes genes from the peroxide metabolism, redox balance, and manganese uptake [92, 93]. Since the OxyS was not activated while E. coli was grown at high dissolved oxygen concentrations (Fig. 6a), it is an indication that the $\mathrm{H}_{2} \mathrm{O}_{2}$ level was low, and the activation of the SoxRS system together with the SOD (Fig. 6b) was sufficient to protect the cells from the oxidative stress allowing the cells to continue growing without the contribution of OxyS [90]. The response to oxidative stress in high cell density cultures is an example where the posttranscriptional regulation mediated by this sRNA differs from the physiological response observed in low density cultures exposed to external induced stress.

\section{Summary}

Changes in growth conditions are known to generate stress responses in $E$. coli by a variety of complex mechanisms, among them the posttranscriptional response mediated by small RNAs. By using experimental approaches, high-throughput computational searches [94], shotgun cloning [95] and tiling array analyses [22], 

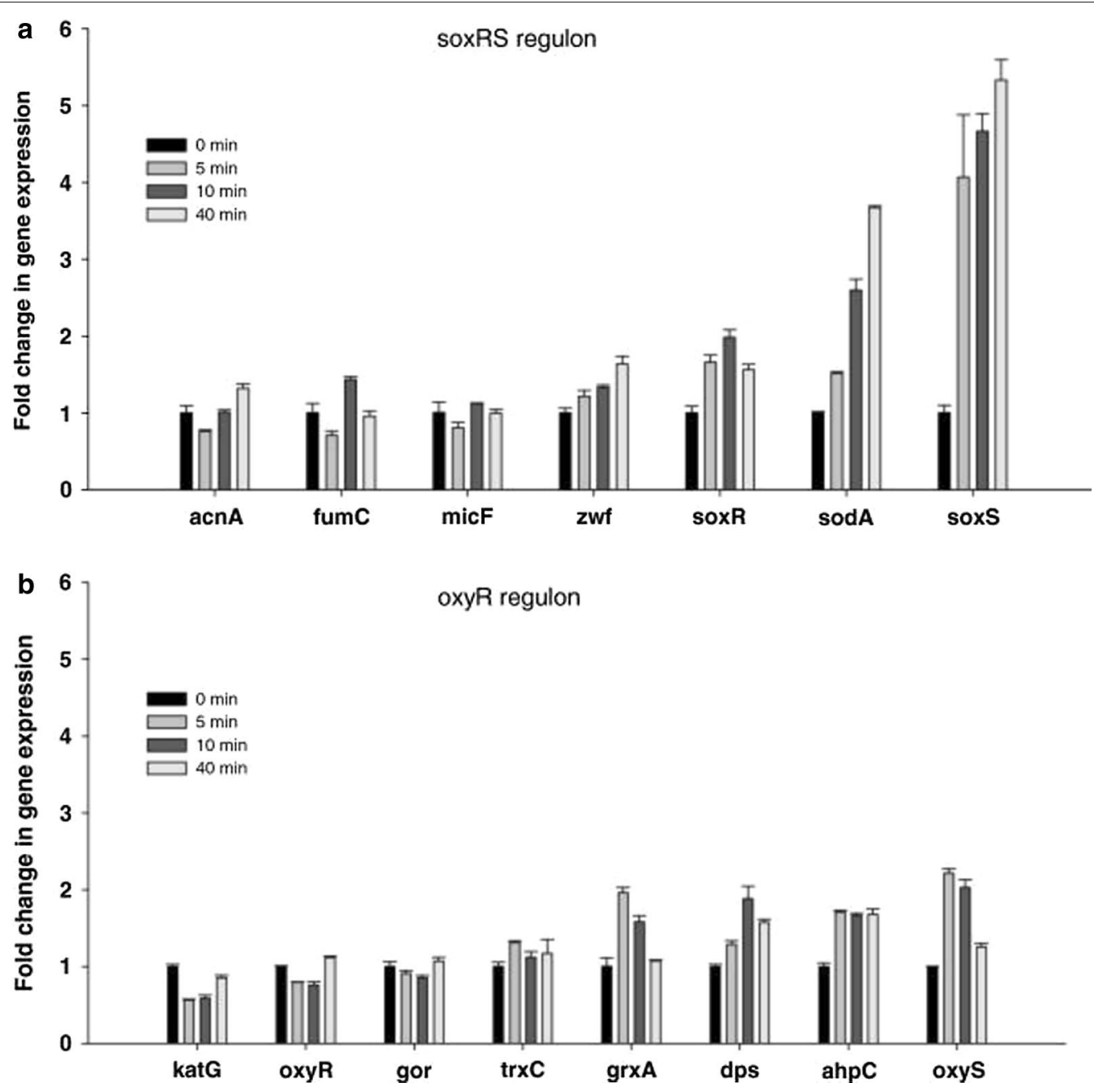

Fig. 5 Time course expression of selected genes controlled by SoxRS and OxyR regulons during E. coli $\mathrm{K}-12 \mathrm{MG}_{1655}$ growth at 30 and $300 \%$ dO 2 . a SoxRS controlled genes, b OxyR controlled genes, changes in mRNA were analyzed 0, 5, 10, and 40 min after $\mathrm{dO}_{2}$ shift from 30 to $300 \%$. Error bars represent standard deviations between triplicate analyses (Taken from [90])

123 sRNAs have been experimentally verified and registered in the Rfam database and specifically for $E$. coli $\mathrm{K}-12$ in the RegulonBD database [96, 97]. Although considerable work has been done on sRNA expression in $E$. coli, not much effort was directed towards utilizing small RNAs for creating $E$. coli strains resistant to growth-related stress conditions. Stress conditions are likely to occur when the bacteria are propagated at high density growth for production of biologicals. In this short review, we summarize the modifications of small RNA expression that were implemented to create $E$. coli strains resistant to stress conditions caused by glucose concentration, low $\mathrm{pH}$, and pure $\mathrm{O}_{2}$. The strains overexpressing SgrS and GadY showed improved cell growth and an additional decrease in acetate productions. This indicates that manipulations at the posttranscriptional regulation, mediated by sRNAs, improve cell growth by enhancing cell resistance to low $\mathrm{pH}$, and by decreasing the production of undesirable metabolites. This observation opens up ample opportunities to modify $E$. coli at the posttranscriptional level without affecting cell growth through the modifications of metabolic pathways. The current summary describes the effect of sRNAs only on glucose and $\mathrm{pH}$, but there are certainly more stress-creating conditions that can affect the bacterial growth that need to be evaluated in industrial settings. We believe that the application of transcriptional regulation mediated by sRNA will improve large-scale productions of recombinant 

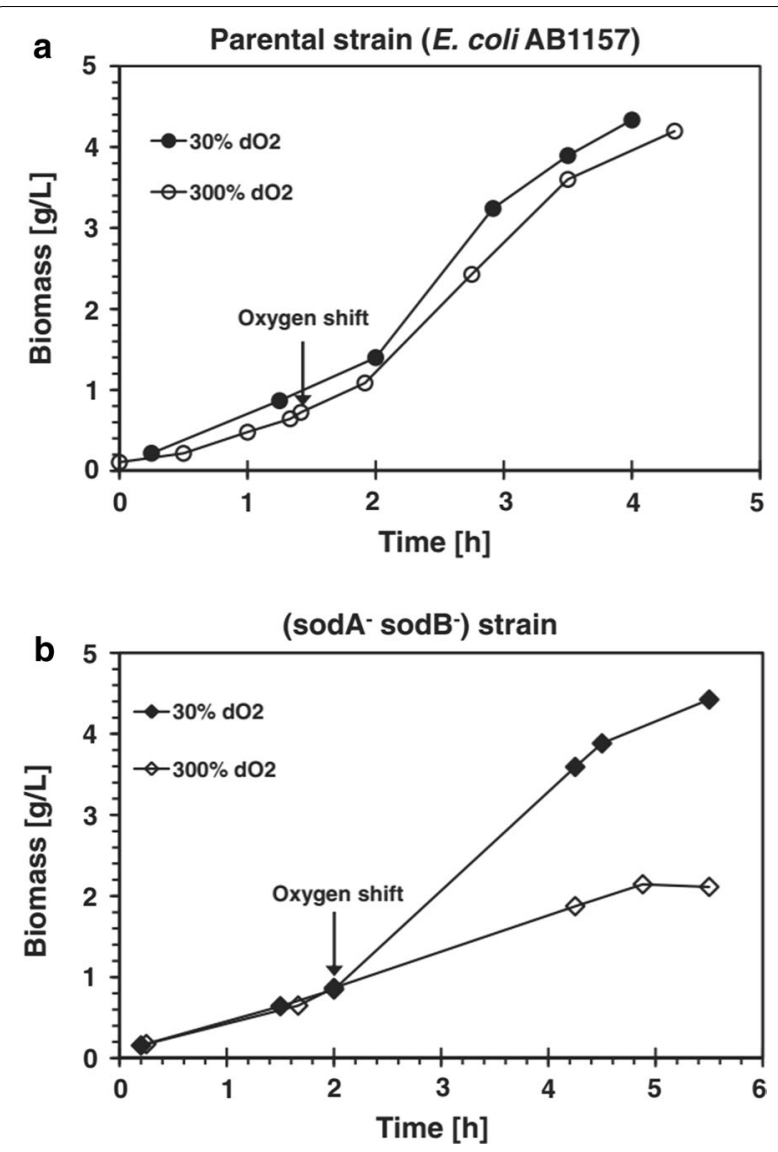

Fig. 6 Effects of dissolved oxygen shift on growth of a E. coli AB1157 and $\mathbf{b}$ SOD deficient mutant. The arrows indicate when $\mathrm{dO}_{2}$ was increased from 30 to $300 \%$. The $30 \% \mathrm{dO}_{2}$ reference culture (circle) in (a) parental strain and (diamond) in (b) sod $\mathrm{A}^{-}$sodB $^{-}$strain (Taken from [90])

proteins in E. coli where environmental changes are likely to occur.

\section{Abbreviations}

aMG: alpha methyl glucoside; FhIA: format hydrogen lyase activator; GDS: glutamate decarboxylase system; LDS: lysine decarboxylase system; SOD: manganese superoxide dismutase; MES: 2-(N-morpholino)ethanesulfonic acid; PTS: phosphotransferase system; ROS: reactive oxygen species.

\section{Authors' contributions}

AN and JS wrote the manuscript together, AN performed the literature search and assembled the relevant published results. JS reviewed and edited the information collected. Both authors read and approved the final manuscript.

\section{Author details}

1 Biotechnology Core Laboratory, NIDDK, NIH, Bethesda, MD 20892, USA.

2 Present Address: MilliporeSigma, Carlsbad, CA 92009, USA.

\section{Acknowledgements}

The authors would like to thank Dr. N. Majdalani for valuable comments and Mrs. D. Livnat for editorial assistance.

\section{Competing interests}

The authors declare that they have no competing interests.

\section{Availability of data and materials}

The datasets supporting the conclusions of this article are included within the article.

\section{Consent for publication \\ Not applicable.}

\section{Ethics approval and consent to participate}

Not applicable.

\section{Funding}

Funding was provided by the intramural program of the NIDDK/NIH.

\section{Publisher's Note}

Springer Nature remains neutral with regard to jurisdictional claims in published maps and institutional affiliations.

Received: 6 July 2017 Accepted: 2 November 2017

Published online: 14 November 2017

\section{References}

1. Graumann K, Premstaller A. Manufacturing of recombinant therapeutic proteins in microbial systems. Biotechnol J. 2006;1:164-86.

2. Sivashanmugam A, Murray V, Cui C, Zhang Y, Wang J, Li Q. Practical protocols for production of very high yields of recombinant proteins using Escherichia coli. Protein Sci. 2009:18:936-48.

3. Rosano GL, Ceccarelli EA. Recombinant protein expression in Escherichia coli: advances and challenges. Front Microbiol. 2014;5:172.

4. Baeshen MN, Al-Hejin A, Bora RS, Ahmed MM, Ramadan HA, Saini KS, Baeshen NA, Redwan EM. Production of biopharmaceuticals in E. coli: current scenario and future perspectives. J Microbiol Biotechnol. 2015;25:953-62.

5. Redwan ERM. Cumulative updating of approved biopharmaceuticals. Hum Antibodies. 2007;16(3-4):137-58.

6. Sanchez-Garcia L, Martín L, Mangues R, Ferrer-Miralles N, Vázquez E, Villaverde A. Recombinant pharmaceuticals from microbial cells: a 2015 update. Microb Cell Fact. 2016;1615:33.

7. Bauer S, Shiloach J. Maximal exponential growth rate and yield of E. coli obtainable in a bench-scale fermentor. Biotechnol Bioeng. 1974;16(7):933-41.

8. Ferrer-Miralles N, Domingo-Espin J, Corchero JL, Vazquez E, Villaverde A. Microbial factories for recombinant pharmaceuticals. Microb Cell Fact. 2009;8:17.

9. Shimizu K. Metabolic regulation of a bacterial cell system with emphasis on Escherichia coli metabolism. ISRN Biochem. 2013;2013:1-47.

10. Delaney JM. A grpE mutant of Escherichia coli is more resistant to heat than the wild-type. J Gen Microbiol. 1990;136:797-801.

11. Carneiro S, Ferreira EC, Rocha I. Metabolic responses to recombinant bioprocesses in Escherichia coli. J Biotechnol. 2013;164(3):396-408.

12. Chong H, Yeow J, Wang I, Song H, Jiang R. Improving acetate tolerance of Escherichia coli by rewiring its global regulator CAMP receptor protein (CRP). PLOS ONE. 2013;8(10):e77422.

13. Lennen RM, Herrgård MJ. Combinatorial strategies for improving multiple-stress resistance in industrially relevant Escherichia coli strains. Appl Environ Microbiol. 2014;80:6223-42.

14. Chung HJ, Bang W, Drake MA. Stress response of Escherichia coli. Compr Rev Food Sci Food Saf. 2006;5:52-64.

15. Persson O, Valadi A, Nystrom T, Farewell A. Metabolic control of the Escherichia coli universal stress protein response through fructose6-phosphate. Mol Microbiol. 2007;65:968-78.

16. Repoila F, Darfeuille F. Small regulatory non-coding RNAs in bacteria: physiology and mechanistic aspects. Biol Cell. 2009;101:117-31.

17. Beisel CL, Storz G. Base pairing small RNAs and their roles in global regulatory networks. FEMS Microbiol Rev. 2010;34:866-82.

18. Guillier M, Gottesman S. Remodelling of the Escherichia coli outer membrane by two small regulatory RNAs. Mol Microbiol. 2006;59(1):231-47.

19. Lalaouna D, Simoneau-Roy M, Lafontaine D, Massé E. Regulatory RNAs and target mRNA decay in prokaryotes. Biochim Biophys Acta. 2013;1829:742-7. 
20. Hoe CH, Raabe CA, Rozhdestvensky TS, Tang TH. Bacterial sRNAs: regulation in stress. Int J Med Microbiol. 2013;303:217-29.

21. Vogel J, Wagner EG. Target identification of small noncoding RNAs in bacteria. Curr Opin Microbiol. 2007;10(3):262-70.

22. Tjaden B. Prediction of small, noncoding RNAs in bacteria using heterogeneous data. J Math Biol. 2008;56(1-2):183-200.

23. Vogel J, Sharma CM. How to find small non-coding RNAs in bacteria. Biol Chem. 2005;386:1219-38.

24. Richards GR, Vanderpool CK. Molecular call and response: the physiology of bacterial small RNAs. Biochim Biophys Acta. 2011;1809:525-31.

25. Chen S, Zhang A, Blyn LB, Storz G. MicC, a second small-RNA regulator of Omp protein expression in Escherichia coli. J Bacteriol. 2004;186:6689-97.

26. Andersen J, Forst SA, Zhao K, Inouye M, Delihas N. The function of micF RNA. micF RNA is a major factor in the thermal regulation of OmpF protein in Escherichia coli. J Biol Chem. 1989;264(30):17961-70.

27. Sledjeski DD, Gupta A, Gottesman S. The small RNA, DsrA, is essential for the low temperature expression of RpoS during exponential growth in Escherichia coli. EMBO J. 1996:15:3993-4000.

28. Majdalani N, Cunning C, Sledjeski D, Elliott T, Gottesman S. DsrA RNA regulates translation of RpoS message by an anti-antisense mechanism, independent of its action as an antisilencer of transcription. Proc Natl Acad Sci USA. 1998;95(21):12462-7.

29. Lease RA, Belfort M. Riboregulation by DsrA RNA: trans-actions for global economy. Mol Microbiol. 2000;38:667-72.

30. Lease RA, Woodson SA. Cycling of the Sm-like protein Hfa on the DsrA small regulatory RNA. J Mol Biol. 2004;344:1211-23.

31. Aiba H, Matsuyama SI, Mizuno T, Mizushima S. Function of micF as an antisense RNA in osmoregulatory expression of the ompF gene in Escherichia coli. J Bacteriol. 1987;169:3007-12.

32. Coyer J, Andersen J, Forst SA, Inouye M, Delihas N. micF RNA in ompB mutants of Escherichia coli: different pathways regulate micF RNA levels in response to osmolarity and temperature change. J Bacteriol. 1990;172:4143-50.

33. Majdalani N, Chen S, Murrow J, St John K, Gottesman S. Regulation of RpoS by a novel small RNA: the characterization of RprA. Mol Microbiol. 2001;39(5):1382-94

34. Madhugiri R, Basineni SR, Klug G. Turn-over of the small non-coding RNA RprA in E. coli is influenced by osmolarity. Mol Genet Genom. 2010;284(4):307-18.

35. Massé E, Gottesman S. A small RNA regulates the expression of genes involved in iron metabolism in Escherichia coli. Proc Natl Acad Sci USA. 2002;99:4620-5.

36. Massé E, Vanderpool CK, Gottesman S. Effect of RyhB small RNA on global iron use in Escherichia coli. J Bacteriol. 2005:187(20):6962-71.

37. Altuvia S, Weinstein-Fischer D, Zhang A, Postow L, Storz G. A small, stable RNA induced by oxidative stress: role as a pleiotropic regulator and antimutator. Cell. 1997;90(1):43-53.

38. Durand S, Storz G. Reprogramming of anaerobic metabolism by the FnrS small RNA. Mol Microbiol. 2010;75(5):1215-31.

39. Boysen A, Møller-Jensen J, Kallipolitis B, Valentin-Hansen P, Overgaard M. Translational regulation of gene expression by an anaerobically induced small noncoding RNA in Escherichia coli. J Biol Chem. 2010:285(14):10690-702.

40. Vanderpool CK, Gottesman S. Involvement of a novel transcriptional activator and small RNA in post-transcriptional regulation of the glucose phosphoenolpyruvate phosphotransferase system. Mol Microbiol. 2004:54:1076-89

41. Wadler CS, Vanderpool CK. A dual function for a bacterial small RNA: SgrS performs base pairing-dependent regulation and encodes a functional polypeptide. Proc Natl Acad Sci USA. 2007;104:20454-9.

42. De Lay N, Gottesman S. The Crp-activated small noncoding regulatory RNA CyaR (RyeE) links nutritional status to group behavior. J Bacteriol. 2009;191(2):461-76

43. Papenfort K, Vogel J. Sweet business: Spot42 RNA networks with CRP to modulate catabolite repression. Mol Cell. 2011;41(3):245-6.

44. Møller T, Franch T, Udesen C, Gerdes K, Valentin-Hansen P. Spot 42 RNA mediates discoordinate expression of the E. coli galactose operon. Genes Dev. 2002;16(13):1696-706.

45. Opdyke JA, Kang JG, Storz G. GadY, a small-RNA regulator of acid response genes in Escherichia coli. J Bacteriol. 2004;186:6698-705.
46. Tramonti A, De Canio M, De Biase D. GadX/GadW-dependent regulation of the Escherichia coli acid fitness island: transcriptional control at the gadY-gadW divergent promoters and identification of four novel $42 \mathrm{bp}$ GadX/GadW-specific binding sites. Mol Microbiol. 2008;70:965-82.

47. Bak G, Han K, Kim D, Lee Y. Roles of rpoS-activating small RNAs in pathways leading to acid resistance of Escherichia coli. Microbiologyopen. 2014;3(1):15-28.

48. Lease RA, Smith D, McDonough K, Belfort M. The small noncoding DsrA RNA is an acid resistance regulator in Escherichia coli. J Bacteriol. 2004;186(18):6179-85.

49. Booth IR, Louis P. Managing hypoosmotic stress: aquaporins and mechanosensitive channels in Escherichia coli. Curr Opin Microbiol. 1999;2(2):166-9.

50. Battesti A, Majdalani N, Gottesman S. The RpoS-mediated general stress response in Escherichia coli. Annu Rev Microbiol. 2011;65:189-213.

51. Porcheron G, Dozois CM. Interplay between iron homeostasis and virulence: Fur and RyhB as major regulators of bacterial pathogenicity. Vet Microbiol. 2015:179(1-2):2-14.

52. Jacques JF, Jang S, Prévost K, Desnoyers G, Desmarais M, Imlay J, Massé E. RyhB small RNA modulates the free intracellular iron pool and is essential for normal growth during iron limitation in Escherichia coli. Mol Microbiol. 2006:62(4):1181-90.

53. Ma Z, Richard H, Tucker DL, Conway T, Foster JW. Collaborative regulation of Escherichia coli glutamate-dependent acid resistance by two AraC-like regulators, GadX and GadW (YhiW). J Bacteriol. 2002;184:7001-12.

54. Waters LS, Storz G. Regulatory RNAs in bacteria. Cell. 2009;136:615-28.

55. Foster JW. Escherichia coli acid resistance: tales of an amateur acidophile. Nat Rev Microbiol. 2004;2:898-907.

56. Vanderpool CK, Gottesman S. The novel transcription factor SgrR coordinates the response to glucose-phosphate stress. J Bacteriol. 2007:189(6):2238-48

57. Rice JB, Vanderpool CK. The small RNA SgrS controls sugar-phosphate accumulation by regulating multiple PTS genes. Nucleic Acids Res. 2011;39:3806-19.

58. Vanderpool CK. Physiological consequences of small RNA mediated regulation of glucose-phosphate stress. Curr Opin Microbiol. 2007;10:146-51.

59. Gottesman S. Micros for microbes: non-coding regulatory RNAs in bacteria. Trends Genet. 2005:21:399-404.

60. Kimata K, Tanaka Y, Inada T, Aiba H. Expression of the glucose transporter gene, ptsG, is regulated at the mRNA degradation step in response to glycolytic flux in Escherichia coli. EMBO J. 2001;20:3587-95.

61. Morita T, El-Kazzaz W, Tanaka Y, Inada T, Aiba H. Accumulation of glucose 6-phosphate or fructose 6-phosphate is responsible for destabilization of glucose transporter mRNA in Escherichia coli. J Biol Chem. 2003;278:15608-14

62. Vanderpool CK, Balasubramanian D, Lloyd CR. Dual-function RNA regulators in bacteria. Biochimie. 2011;93:1943-9.

63. Beisel CL, Storz G. The base-pairing RNA spot 42 participates in a multioutput feedforward loop to help enact catabolite repression in Escherichia coli. Mol Cell. 2011;41(3):286-97.

64. Altuvia S, Zhang A, Argaman L, Tiwari A, Storz G. The Escherichia coli OxyS regulatory RNA represses fhIA translation by blocking ribosome binding. EMBO J. 1998:17(20):6069-75.

65. Zhang A, Altuvia S, Tiwari A, Argaman L, Hengge-Aronis R, Storz G. The oxyS regulatory RNA represses rpos translation by binding $\mathrm{Hfq}$ (HF-1) protein. EMBO J. 1998;17:6061-8.

66. Fu H, Yuan J, Gao H. Microbial oxidative stress response: novel insights from environmental facultative anaerobic bacteria. Arch Biochem Biophys. 2015;15(584):28-35.

67. Imlay JA. Cellular defenses against superoxide and hydrogen peroxide. Annu Rev Biochem. 2008;77:755-76.

68. Cunningham L, Gruer MJ, Guest JR. Transcriptional regulation of the aconitase genes (acnA and $\mathrm{acn} B$ ) of Escherichia coli. Microbiology. 1997;143:3795-805.

69. Gu M, Imlay JA. The SoxRS response of Escherichia coli is directly activated by redox-cycling drugs rather than by superoxide. Mol Microbiol. 2011;79:1136-50

70. Shiloach J, Fass R. Growing E. coli to high cell density-a historical perspective on method development. Biotechnol Adv. 2005;23(5):345-55. 
71. Gosset G. Improvement of Escherichia coli production strains by modification of the phosphoenolpyruvate:sugar phosphotransferase system. Microb Cell Fact. 2005;4(1):14

72. Chou CH, Bennett GN, San KY. Effect of modified glucose uptake using genetic engineering techniques on high-level recombinant protein production in Escherichia coli dense cultures. Biotechnol Bioeng. 1994:44:953-60.

73. Han C, Zhang WC, You S, Huang LY. Knockout of the ptsG gene in Escherichia coli and cultural characterization of the mutants. Sheng Wu Gong Cheng Xue Bao. 2004;20:16-20.

74. Lara AR, Caspeta L, Gosset G, Bolívar F, Ramírez OT. Utility of an Escherichia coli strain engineered in the substrate uptake system for improved culture performance at high glucose and cell concentrations: an alternative to fed-batch cultures. Biotechnol Bioeng. 2008;99(4):893-901.

75. Wong MS, Wu S, Causey TB, Bennett GN, San KY. Reduction of acetate accumulation in Escherichia coli cultures for increased recombinant protein production. Metab Eng. 2008;2:97-108.

76. Son YJ, Phue JN, Trinh LB, Lee SJ, Shiloach J. The role of Cra in regulating acetate excretion and osmotic tolerance in E. coli $\mathrm{K}-12$ and E. coli B at high density growth. Microb Cell Fact. 2011;10:52.

77. Negrete A, Ng WI, Shiloach J. Glucose uptake regulation in E. coli by the small RNA SgrS: comparative analysis of E. coli K-12 (JM109 and MG1655) and E. coli B (BL21). Microb Cell Fact. 2010;9:75.

78. Phue J, Noronha SB, Hattacharyya R, Wolfe AJ, Shiloach J. Glucose metabolism at high density growth of $E$. coli B and $E$. coli $\mathrm{K}$ : differences in metabolic pathways are responsible for efficient glucose utilization in $E$. coli B as determined by microarrays and Northern blot analyses. Biotechnol Bioeng. 2005;90(7):805-20.

79. Negrete A, Majdalani N, Phue JN, Shiloach J. Reducing acetate excretion from E. coli K-12 by over-expressing the small RNA SgrS. N Biotechnol. 2013;30(2):269-73.

80. Wolfe AJ. The acetate switch. Microbiol Mol Biol Rev. 2005;69(1):12-50.

81. Negrete A, Shiloach J. Constitutive expression of the sRNA GadY decreases acetate production and improves E. coli growth. Microb Cell Fact. 2015;14:148.

82. Sieblist C, Jenzsch M, Pohlscheidt M, Lübbert A. Insights into large-scale cell-culture reactors: I. Liquid mixing and oxygen supply. Biotechnol J. 2011;6(12):1532-46.

83. Hirakawa $H$, Hayashi-Nishino M, Yamaguchi A, Nishino K. Indole enhances acid resistance in Escherichia coli. Microb Pathog. 2010;49(3):90-4.

84. Russell JB. Another explanation for the toxicity of fermentation acids at low pH: anion accumulation versus uncoupling. J Appl Bacteriol. 1992;73:363-70
85. Storz G, Zheng M. Oxidative stress. In: Storz G, Hengge-Aronis R, editors. Bacterial stress responses. Washington, DC: ASM Press; 2000. p. 47-59.

86. Pomposiello PJ, Bennik MHJ, Demple B. Genome-wide transcriptional profiling of the Escherichia coli responses to superoxide stress and sodium salicylate. J Bacteriol. 2001;183:3890-902.

87. Zheng M, Wang X, Templeton LJ, Smulski DR, LaRossa R, Storz G. DNA microarray-mediated transcriptional profiling of the Escherichia coli response to hydrogen peroxide. J Bacteriol. 2001;183:4562-70.

88. Castan A, Nasman A, Enfors SO. Oxygen enriched air supply in Escherichia coli processes: production of biomass and recombinant human growth hormone. Enzyme Microb Technol. 2002;30:847-54.

89. Lara AR, Knabben I, Regestein L, Sassi J, Caspeta L, Ramirez OT, Buchs J. Comparison of oxygen enriched air vs. pressure cultivations to increase oxygen transfer and to scale-up plasmid DNA production fermentations. Eng Life Sci. 2011;3:1-5.

90. Baez A, Shiloach J. Escherichia coli avoids high dissolved oxygen stress by activation of SoxRS and manganese-superoxide dismutase. Microb Cell Fact. 2013;12:23.

91. Liochev SI, Benov L, Touati D, Fridovich I. Induction of the soxRS regulon of Escherichia coli by superoxide. J Biol Chem. 1999;274:9479-81.

92. Storz G, Tartaglia LA, Ames BN. The OxyR regulon. Antonie Van Leeuwenhoek. 1990;58(3):157-61.

93. Mongkolsuk S, Helmann JD. Regulation of inducible peroxide stress responses. Mol Microbiol. 2002;45(1):9-15.

94. Saetrom P, Sneve R, Kristiansen KI, Snove O, Grunfeld T, Rognes T, Seeberg E. Predicting non-coding RNA genes in Escherichia coli with boosted genetic programming. Nucleic Acids Res. 2005;33(10):3263-70.

95. Vogel J, Bartels V, Tang TH, Churakov G, Slagter-Jager JG, Huttenhofer A, Wagner EG. RNomics in Escherichia coli detects new sRNA species and indicates parallel transcriptional output in bacteria. Nucleic Acids Res. 2003;31(22):6435-43.

96. Nawrocki EP, Burge SW, Bateman A, Daub J, Eberhardt RY, Eddy SR, Floden EW, Gardner PP, Jones TA, Tate J, Finn RD. Rfam 12.0: updates to the RNA families database. Nucleic Acids Res. 2014. https://doi.org/10.1093/nar/ gku1063.

97. Gama-Castro S, Jimenez-Jacinto V, Peralta-Gil M, Santos-Zavaleta A, Penaloza-Spinola MI, Contreras-Moreira B, Segura-Salazar J, Muniz-Rascado L, Martinez-Flores I, Salgado H, et al. RegulonDB (version 6.0): gene regulation model of Escherichia coli K-12 beyond transcription, active (experimental) annotated promoters and Textpresso navigation. Nucleic Acids Res. 2008;3(Database):D120-4.

\section{Submit your next manuscript to BioMed Central and we will help you at every step:}

- We accept pre-submission inquiries

- Our selector tool helps you to find the most relevant journal

- We provide round the clock customer support

- Convenient online submission

- Thorough peer review

- Inclusion in PubMed and all major indexing services

- Maximum visibility for your research

Submit your manuscript at www.biomedcentral.com/submit
BioMed Central 